\title{
Pengaruh Sistem Informasi Akuntansi Terhadap Efektivitas Pengendalian Piutang Pada PT. Wijaya Kusuma Terang Perkasa
}

\author{
R.M. Jukadi Natalegawa ${ }^{1}$, Setiawan Gunadi ${ }^{2}$ \\ ${ }^{1,2}$ Program Studi S1 Akuntansi \\ ${ }^{1,2}$ Sekolah Tinggi Ilmu Ekonomi Tridharma, Jl.Martanegara No,60 Bandung \\ Email : jukadi@gmail.com ${ }^{1}$, setiawang@stietridharma.ac.id ${ }^{2}$
}

\begin{abstract}
ABSTRAK
Penelitian ini termasuk penelitian asosiatif kausal. Terdapat satu variabel bebas yaitu sistem informasi akuntansi dan variabel terikat yaitu efektivitas Pengendalian Piutang yang secara keseluruhan dikembangkan menjadi 4 indikator. Data primer diperlukan sebagai dasar analisis dan data sekunder merupakan data primer yang diolah lebih lanjut. Sedangkan teknik pengumpulan datanya adalah kuesioner, observasi dan wawancara. Teknik analisis yang digunakan adalah regresi linear sederhana. Tujuan Penelitian ini adalah untuk mengetahui bagaimana pengaruh sistem informasi akuntansi terhadap efektivitas Pengendalian Piutang.

Koefisien bernilai positif artinya terjadi hubungan positif antara variabel sistem informasi akuntansi dengan efektivitas Pengendalian Piutang. Semakin baik sistem informasi akuntansi yang digunakan maka akan meningkatkan efektivitas Pengendalian Piutang pada perusahaan terkait.
\end{abstract}

Kata Kunci : Sistem Informasi Akuntansi, Efektivitas Pengendalian Piutang

\section{ABSTRACT}

This research includes causal associative research. There is one independent variable, namely the accounting information system and the dependent variable, namely the effectiveness of Receivable Control which as a whole is developed into 4 indicators. Primary data is needed as a basis for analysis and secondary data is primary data which is further processed. While the data collection techniques are questionnaires, observations and interviews. The analysis technique used is simple linear regression. The purpose of this study was to determine how the influence of accounting information systems on the effectiveness of Accounts Receivable Control.

The positive coefficient means that there is a positive relationship between accounting information system variables and the effectiveness of Accounts Receivable Control. The better the accounting information system used, it will increase the effectiveness of Receivable Control in related companies.

Keywords: Accounting Information System, Effectiveness of Accounts Receivable Control 


\section{PENDAHULUAN}

Seperti tujuan awal diciptakannya teknologi yang berperan dalam segala bidang di industri khususnya yakni sebagai alat atau hal yang mempermudah segala jenis kegiatan yang ada di dalamnya. Seperti dalam kegiatan berbisnis banyak yang mengeluhkan dalam hal pencatatan laporan keuangan yang sering terjadi kesalahan atau human error yang dapat membuat setiap pengambilan keputusan yang diambil oleh pemilik bisnis menjadi keliru karena seorang pemilik bisnis akan mengambil keputusan berdasarkan laporan keuangan yang dimiliki perusahaan sedangkan laporan keuangan yang dijadikan sebagai acuan memiliki kekurangan atau kesalahan yang cukup fatal dengan otomatis juga keputusan yang diambil akan ikut menjadi keliru.

Atas latar belakang itu semua banyak ahli di bidang sistem informasi membuat sebuah jalan keluar berupa Sistem Informasi Akuntansi untuk membantu pekerjaan para pemilik bisnis agar mengurangi risiko terjadinya kesalahan yang mendasar.

Menurut Walter (2012) pengertian akuntansi adalah sebagai berikut: "Akuntansi merupakan suatu sistem informasi, yang mengukur aktivitas bisnis, memproses data menjadi laporan dan mengkomunikasikan hasilnya kepada pengambil keputusan yang akan membuat keputusan yang dapat mempengaruhi keputusan aktivitas bisnis". Sementara Pengertian Sistem Informasi Akuntansi menurut Mulyadi (2008) menyatakan bahwa: "Sistem Informasi Akuntansi merupakan suatu bentuk sistem informasi yang memiliki tujuan untuk menyediakan informasi bagi pengelola kegiatan usaha, memperbaiki informasi yang dihasilkan oleh sistem yang sudah ada sebelumnya, memperbaiki pengendalian akuntansi dan juga pengecekan internal, serta membantu memperbaiki biaya klerikal dalam pemeliharaan catatan akuntansi”.

Sistem Informasi Akuntansi merupakan sebuah sistem yang digunakan untuk mencatat segala jenis kegiatan dalam perusahaan seperti kegiatan transaksi pada perusahaan, maka dari itu setiap hal yang berkaitan dengan transaksi akan tercatat langsung dalam sistem sehingga ketika ada proses transaksi pembelian secara kredit akan langsung otomatis masuk ke dalam menu tagihan piutang yang bisa di cek langsung oleh bagian pengelola piutang untuk menentukan scheduling yang ditujukan untuk bagian penagihan piutang sehingga proses Pengendalian Piutang yang terjadi dapat diproses secara efektif. Dengan adanya sistem juga dapat meminimalisir 
kesalahan yang terjadi akibat pegawai seperti lupa akan waktu penagihan piutang kepada pelanggan.

PT. Wijaya Kusuma Terang Perkasa sebuah perusahaan yang bergerak dalam bidang perdagangan dan distribusi bahan bangunan dan furniture memiliki masalah yang sama seperti perusahaan lainnya yang bermasalah dengan kurang efektifnya hasil laporan keuangan yang dihasilkan sebelumnya. Berdasarkan uraian yang telah dipaparkan diatas, rumusan masalah yang dapat diajukan dalam penelitian ini adalah:

1. Bagaimana penggunaan Sistem Informasi Akuntansi pada PT. Wijaya Kusuma Terang Perkasa Bandung.

2. Bagaimana efektivitas pencatatan laporan keuangan pada PT. Wijaya Kusuma Terang Perkasa.

3. Apakah terdapat pengaruh antara Sistem Informasi Akuntansi dengan efektivitas pencatatan laporan keuangan pada PT. Wijaya Kusuma Terang Perkasa.

\section{Tinjauan Pustaka}

\section{Pengertian Akuntansi}

Menurut Walter (2012:3) pengertian akuntansi adalah sebagai berikut: “Akuntansi merupakan suatu sistem informasi, yang mengukur aktivitas bisnis, memproses data menjadi laporan dan mengkomunikasikan hasilnya kepada pengambil keputusan yang akan membuat keputusan yang dapat mempengaruhi keputusan aktivitas bisnis”.

\section{Pengertian Sistem}

Pengertian sistem menurut Romney dan Steinbart (2015:3), "Sistem adalah rangkaian dari dua atau lebih komponen-komponen yang saling berhubungan, yang berinteraksi untuk mencapai suatu tujuan. Sebagian besar sistem terdiri dari subsistem yang lebih kecil yang mendukung sistem yang lebih besar".

\section{METODE PENELITIAN}

Metode yang digunakan dalam penelitian ini adalah metode deskrptif dengan analisa kuantitatif. Dalam penelitian ini, yang menjadi objek penelitian adalah Sistem Informasi Akuntansi Pada PT. Wijaya Kusuma Terang Perkasa Bandung yang bergerak di bidang perdagangan dan distribusi bahan bangunan dan furniture. 
Berdasarkan pengertian sampel diatas peneliti memilih sampel berupa laporan piutang pada perusahaan PT. Wijaya Kusuma Terang Perkasa selama 24 bulan kebelakang terhitung sejak bulan Oktober 2020.

Dalam penelitian ini dilakukan beberapa teknik pengumpulan data sebagai berikut: Kuesioner (Angket), Wawancara danObservasi.

\section{HASIL DAN PEMBAHASAN}

\section{A. Hasil Penelitian}

\section{Gambaran Karakteristik Responden}

Responden dengan usia 21 berjumlah 5 , usia 22 berjumlah 4, usia 23 berjumlah 2, usia 24 berjumlah 1. Sementara Responden usia 25 berjumlah 6, usia 27 berjumlah 2. Dan Responden dengan pendidikan terakhir SMA berjumlah 15 orang dan S1 berjumlah 5. Serta Responden dengan jenis kelamin laki-laki berjumlah 8 dan perempuan sejumlah 12 .

\section{Hasil Penelitian}

Hasil rekapitulasi jawaban kuesioner karyawan PT. Wijaya Kusuma Terang Perkasa Bandung pada indikator sistem pelayanan dijelaskan dari alasan responden bahwa sistem informasi dapat dioperasikan pada waktu jam kerja dengan nyamantanpa kendala.

Hasil rekapitulasi jawaban kuesioner karyawan PT. Wijaya Kusuma Terang Perkasa Bandung pada indikator kualitas sistem alasan respoden bahwa sistem informasi akuntansi diperusahaan memiliki kemudahan untuk diakses kapapun saat dibutuhkan.

Hasil rekapitulasi jawaban kuesioner karyawan PT. Wijaya Kusuma Terang Perkasa Bandung pada indikator kualitas informasi dijelaskan dari alasan respon den sesuai kebutuhan perusahaan.

Hasil rekapitulasi jawaban kuesioner karyawan PT. Wijaya Kusuma Terang Perkasa Bandung pada indikator pelaksana kegiatan dijelaskan dari alasan responden bahwa dilakukan proses cross check antara bukti fisik dengan data yang berada pada sistem informasi perusahaan.

Hasil rekapitulasi jawaban kuesioner karyawan PT. Wijaya Kusuma Terang Perkasa Bandung pada indikator hasil dijelaskan dari alasan responden bahwa setiap proses pencatatan piutangmemiliki butki yang disertai tanggal terjadinya piutang. 


\section{B. Uji Data}

\section{Uji Validitas}

\section{Hasil Uji Validitas Sistem Informasi Akuntansi (X)}

Berdasarkan dari hasil pengujian data validitas yang dilakukan penulis didapat nilai Pearson Correlation (r hitung) untuk semua item lebih besar dari 0.444 dan 0.561 maka dapat disimpulkan untuk variabel Sistem Informasi Akuntansi (X) pada semua item tersebut berkorelasi signifikan dengan skor total (dinyatakan valid) dan dapat dijadikan sebagai salah satu alat ukur yang valid dalam proses analisis selanjutnya.

\section{Hasil Uji Validitas Efektivitas Pengendalian Piutang (Y)}

Berdasarkan dari hasil pengujian data validitas yang dilakukan penulis didapat nilai Pearson Correlation (r hitung) untuk semua item lebih besar dari 0.561 maka dapat disimpulkan untuk variabel Efektivitas Pengendalian Piutang (Y) semua item tersebut berkorelasi signifikan dengan skor total (dinyatakan valid) dan dapat dijadikan sebagai salah satu alat ukur yang valid dalam proses analisis selanjutnya.

\section{Uji Reliabilitas}

Semua nilai dari hasil olahan data pada aplikasi melebihi dari 0,6 yang berarti bahwa semua variabel pada penelitian ini reliabel atau memiliki tingkat kepercayaan yang tinggi, atau dapat disimpulkan bahwa kuesioner Sistem Informasi Akuntansi Terhadap Pengendalian Piutang yang telah diuji termasuk reliabel atau handal untuk dipergunakan dalam penelitian ini.

\section{Uji Hipotesis}

\section{Analisis Regresi Linear Sederhana}

Tabel 1. Hasil Perhitungan Analisis Regresi Linear

\begin{tabular}{|c|c|c|c|c|c|}
\hline \multirow{2}{*}{$\begin{array}{l}\text { Mo } \\
\text { del }\end{array}$} & \multicolumn{2}{|c|}{$\begin{array}{c}\text { Unstandardized } \\
\text { Coefficients }\end{array}$} & \multirow{2}{*}{$\begin{array}{c}\begin{array}{c}\text { Standardized } \\
\text { Coefficients }\end{array} \\
\text { Beta } \\
\end{array}$} & \multirow[b]{2}{*}{$\mathbf{t}$} & \multirow[b]{2}{*}{ Sig. } \\
\hline & B & Std. Error & & & \\
\hline Constant & -1.482 & 1.531 & & -0.968 & $\begin{array}{c}.34 \\
6\end{array}$ \\
\hline $\begin{array}{l}\text { Sistem Informasi } \\
\text { Akuntansi (X) }\end{array}$ & 0.268 & 0.017 & 0.964 & 15.398 & $\begin{array}{c}.00 \\
0\end{array}$ \\
\hline
\end{tabular}


Berdasarkan tabel di atas dapat memiliki nilai yang telah diketahui dapat diartikan bahwa angka konstan sebesar -1.842 memiliki arti jika menggunakan Sistem Informasi Akuntansi (X) maka Efektivitas Pengendalian Piutang (Y).

Dan juga angka koefisien regresi sebesar 0.268 mengandung arti bahwa setiap pengunaan 1\% Sistem Informasi Akuntansi (X), maka Efektivitas Pengelolaa Piutang (Y) akan meningkat sebesar 0.268 .

Karena nilai koefisien regresi bernilai positif $(+)$, maka dengan demikian dapat dikatakan bahwa Sistem Informasi Akuntansi (X) berpengaruh positif terhadap Efektivitas Pengendalian Piutang (Y). Sehingga persamaan regresinya adalah $\mathrm{Y}=$ $1.842+0.268 X$.

Selain itu, berdasarkan output pada tabel yang diketahui bahwa nilai signifikan (Sig.) sebesar 0.000 lebih kecil dari < probabilitas 0,05, sehingga dapat disimpulkan bahwa H0 ditolak dan H1 diterima, yang berarti bahwa "Terdapat Pengaruh Sistem Informasi Akuntansi (X) terhadap Efektivitas Pengendalian Piutang (Y)”.

Angka koefisien regresi sebesar 0.268 mengandung arti bahwa setiap pengunaan 1\% Sistem Informasi Akuntansi (X), maka Efektivitas Pengelolaa Piutang (Y) akan meningkat sebesar 0.268 .

Karena nilai koefisien regresi bernilai positif (+), maka dengan demikian dapat dikatakan bahwa Sistem Informasi Akuntansi (X) berpengaruh positif terhadap Efektivitas Pengendalian Piutang (Y). Sehingga persamaan regresinya adalah $\mathrm{Y}=$ $1.842+0.268 \mathrm{X}$

Selain itu, berdasarkan output pada tabel yang diketahui bahwa nilai signifikan (Sig.) sebesar 0.000 lebih kecil dari < probabilitas 0,05, sehingga dapat disimpulkan bahwa H0 ditolak dan H1 diterima, yang berarti bahwa "Terdapat Pengaruh Sistem Informasi Akuntansi (X) terhadap Efektivitas Pengendalian Piutang (Y)”.

\section{SIMPULAN}

1. Sistem pelayanan Informasi PT. Wijaya Kusuma Terang Perkasa Bandung dapat dioperasikan pada waktu jam kerja dengan nyaman tanpa kendala.

\begin{tabular}{ccccccccccc}
\hline \multirow{2}{*}{ Pertanyaan } & \multicolumn{2}{l}{$\begin{array}{l}\text { Sangat Tidak } \\
\text { Setuju }\end{array}$} & Tidak Setuju & Ragu Ragu & Setuju & \multicolumn{2}{c}{$\begin{array}{c}\text { Sangat } \\
\text { Setuju }\end{array}$} \\
\cline { 2 - 11 } Pertanyaan 1 & $\sum$ & $\%$ & $\sum$ & $\%$ & $\sum$ & $\%$ & $\sum$ & $\%$ & $\sum$ & $\%$ \\
\hline
\end{tabular}


2. Kualitas sistem informasi akuntansi di PT. Wijaya Kusuma Terang Perkasa Bandung memiliki kemudahan untuk diakses kapapun saat dibutuhkan.

\begin{tabular}{cccccccccc}
\hline Pertanyaan & \multicolumn{2}{l}{$\begin{array}{l}\text { Sangat Tidak } \\
\text { Setuju }\end{array}$} & $\begin{array}{l}\text { Tidak } \\
\text { Setuju }\end{array}$ & $\begin{array}{c}\text { Ragu } \\
\text { Ragu }\end{array}$ & Setuju & $\begin{array}{c}\text { Sangat } \\
\text { Setuju }\end{array}$ \\
\cline { 2 - 9 } & $\sum$ & $\%$ & $\sum$ & $\%$ & $\sum$ & $\%$ & $\sum$ & $\%$ & $\sum$ \\
\cline { 2 - 9 } Pertanyaan 2 & 0 & 0 & 0 & 0 & 0 & 0 & 17 & 85 & 3 \\
\hline
\end{tabular}

3. Indikator pelaksana kegiatan di PT. Wijaya Kusuma Terang Perkasa Bandung dilakukan proses cross check antara bukti fisik dengan data yang berada pada sistem informasi perusahaan.

\begin{tabular}{|c|c|c|c|c|c|}
\hline Pertanyaan & $\begin{array}{l}\text { Sangat Tidak } \\
\text { Setuju }\end{array}$ & Tidak Setuju & Ragu Ragu & Setuju & $\begin{array}{l}\text { Sangat } \\
\text { Setuju }\end{array}$ \\
\hline & $\sum \quad \%$ & $\sum$ & $\sum$ & $\sum$ & $\sum$ \\
\hline
\end{tabular}

$\begin{array}{lllllllllll}\text { Pertanyaan } 3 & 0 & 0 & 0 & 0 & 0 & 0 & 14 & 70 & 6 & 30\end{array}$

4. Indikator hasil di PT. Wijaya Kusuma Terang Perkasa Bandung mengatakan bahwa setiap proses pencatatan piutang memiliki bukti yang disertai tanggal terjadinya piutang.

\begin{tabular}{rlccccccccc}
\hline \multirow{2}{*}{ Pertanyaan } & \multicolumn{2}{l}{$\begin{array}{l}\text { Sangat Tidak } \\
\text { Setuju }\end{array}$} & $\begin{array}{l}\text { Tidak } \\
\text { Setuju }\end{array}$ & & Ragu Ragu & Setuju & \multicolumn{2}{c}{$\begin{array}{c}\text { Sangat } \\
\text { Setuju }\end{array}$} \\
\cline { 2 - 10 } & $\sum$ & $\%$ & $\sum$ & $\%$ & $\sum$ & $\%$ & $\sum$ & $\%$ & $\sum$ & $\%$ \\
\hline Pertanyaan 4 & 0 & 0 & 0 & 0 & 0 & 0 & 17 & 85 & 3 & 15 \\
\hline
\end{tabular}

\section{DAFTAR PUSTAKA}

Bodnar, G. H. (2014). Accounting Information Systems, Eleventh Edition. Pearson Education.

Dwi Martiani, d. (2014). Akuntansi Keuangan Menengah Berbasis PSAK. Jakarta: Salemba Empat.

Harrison Jr., W. T. (et al. 2012). Akuntansi Keuangan IFRS Edisi Kedelapan Jilid! Jakarta: Erlangga.

Mardiasmo. (2014). Akuntansi Sektor Publik. Edisi Lima. Cetakan Keempat. Yogyakarta: CV Andi Offset.

Mardiasmo. (2016). Perpajakan Edisi Revisi. Yogyakarta: Andi Offset.

Mulyadi. (2008). Sistem Akuntansi. Jakarta: Salemba Empat. 
Roomney, M. B. (2015). Sistem Informasi Akuntansi, Edisi 13,. Jakarta : Salemba Empat.

Sugiyono. (2004). Statistika Untuk Penelitian. Bandung: Alfabeta.

Sugiyono. (2015). Metode Penelitian Kombinasi (Mix Methods). Bandung: Alfabeta.

Sugiyono. (2017). Metode Penelitian Kuantitatif, Kualitatif, dan R\&D. Bandung: Alfabeta.

Sugiyono. (2018). Metode Penelitian Kuantitatif. Bandung: Alfabeta.

Susanto, A. (2013). Sistem Informasi Akuntansi, Struktur Pengendalian Resiko Pengembangan, Edisi Perdana. Bandung: Lingga Jaya. 